\title{
FROM THE DESK OF EDITOR in CHIEF
}

(J Bangladesh Coll Phys Surg 2012; 30: 60)

Let me start by thanking all of you who have contributed to the journal over the years. It is you who have helped us to bring out the issues without hindrance. Still a lot is left to ask for. In-spite of all your effort we are getting very few quality original articles. This is due to the lack of interest in performing original research among the young physicians. It is the younger generation who are going to lead the future of scientific commons of this country and they should come up with new and innovative ideas for the advancement of medical science in Bangladesh. I therefore urge the new generation of specialists to dedicate more time in research work and this will ensure publication of papers of international stature.

HAM Nazmul Ahasan

Editor-In-Chief 